\title{
SOFÍA DE LOS PRESAGIOS, ESPACIO DE ENCUENTRO DE DOS ESTRUCTURAS PSICOSOCIALES: MATRIARCADO Y PATRIARCADO
}

\author{
Marisol Gutiérrez Rojas
}

\begin{abstract}
RESUMEN
Se examina la presencia de dos estructuras psicosociales en permanente tensión en el mundo narrativo de Sofía de los presagios (Gioconda Belli 1990): la estructura matriarcal (en términos de J.J. Bachofen, la estructura psicosocial del mundo ginecocrático) y la estructura psicosocial del mundo patriarcal.

Se hurga en las huellas del mundo ginecocrático evidenciadas en símbolos, mitos y ritos ligados a las fuerzas telúricas, la sensorialidad y la magia; por ejemplo, la ponderación de la Madre Antigua, la presencia de los círculos y las espirales y el simbolismo de la luna como lugar de mediación entre la tierra y el sol y como principio femenino. Asimismo, se evidencian elementos ocultos, marginados o considerados opuestos a los valores del mundo patriarcal, como los artificios que hicieron posible la conversión de mujeres como las comadronas, herbolarias y curanderas en brujas; los mecanismos del sistema patriarcal que influyen en el deber ser y dictan normas de marcado acento heterosexual y condena de la homosexualidad. Finalmente, se analiza la figura de Sofía desde su diferencia (bruja) dentro de la diferencia (mundo supersticioso y arcaico del Diriá frente a una Nicaragua revolucionaria).
\end{abstract}

\begin{abstract}
This article discusses the presence of two psyco-social structures in permanent tension in the narrative world of Sofía de los presagios (Gioconda Belli 1990): the matriarchal structure (the psychosocial structure of the gynecocratic world, in terms of J.J. Bachofen) and the psychosocial structure of the patriarchal world.

The traces of the gynecocratic world are examined as evidenced in symbols, myths and rituals associated with telluric forces, sensoriality and magic; for example, the pondering of the Ancient Mother, the presence of circles and spirals and the symbolism of the Moon as a means of mediation between the Earth and the Sun and as a feminine principle. Hidden and margined elements or elements considered to be opposite to the values of the patriarchal world, such as the artifices which made possible the conversion of such women as midwifes, herbalists and quack doctors into witches, are also studied, as well as the mechanisms used in the patriarchal system to influence the "must be" and to establish social norms which validate heterosexual conduct and condemn homosexuality. Finally, the figure of Sofia is analyzed from her difference (witch) among the difference (the supersticious and archaic world of Diriá vis-à-vis revolutionary Nicaragua).
\end{abstract}




\section{Elementos estructurantes del mundo ginecocrático en Sofía de los presagios}

En 1990, aparece Sofía de los presagios, segunda incursión narrativa de la escritora nicaragüense Gioconda Belli. La novela no solo tiene como eje temático a la mujer, sino que parece responder a lo que Márgara Russotto denomina "el rescate de una arqueología ignota para estimular una cultura emergente" (1990: 49); de ahí que la novela se nos presente como un espacio de cruce de visiones de mundo, de culturas y de estructuras psicosociales que desembocan en la formulación de un nuevo paradigma sociocultural que visibiliza a Eros (poder femenino) y estimula una revisión profunda y novedosa de las estructuras de relación entre los sexos: se plantea una relación dialógica con la naturaleza (ya no como objeto sino como sujeto vocal); se pondera el poder femenino manifiesto en la presencia de la Diosa Madre y sus representantes telúricas: las mujeres mágicas (brujas); y se formula una propuesta de identidad personal y colectiva (diálogo intergenérico) en el marco de una sociedad emancipada y armónica. Asimismo, Sofía de los presagios es un espacio escritural en el que se desata una transgresión en los planos teológico, temporal, astral y sexual, de esta manera: frente a las normas coercitivas de la religión católica imperante en Occidente se levanta el poder creativo de la magia y los ritos ancestrales; frente al tiempo lineal cristiano se propone una continuidad cíclica, pero en progreso (espiral); frente al predominio de los astros de signo masculino se propone una revaloración de la luna como símbolo del poder femenino; y frente a la norma heterosexual vigente, que dicta los patrones de comportamiento para cada sexo (masculino y femenino), se propone una relectura de los roles asignados y una reflexión acerca de otras opciones sexuales.

Interesa destacar entre los fundamentos teóricos que permiten abordar este análisis y, en especial, atender la estructura formal del documento en tanto articulación y desarticulación de elementos estructurantes del matriarcado y del patriarcado, el "rescate" de los planteamientos del jurista y mitólogo suizo Johann Jakob Bachofen. Este autor, que en la actualidad sufre una interesante reinterpretación ligada especialmente a los movimientos ecofeministas, plantea en el siglo XIX la existencia primigenia de un "matriarcado" como fase sociocultural de la humanidad, caracterizada por la ginecocracia, es decir, por el dominio de la mujer en el nivel familiar y social. Este mundo ginecocrático tiene un fundamento religioso que enaltece a la Madre telúrica y, en consecuencia, a su representante terrena-mortal, la mujer (Bachofen 1988:75). Bachofen sostiene que la historia de la ginecocracia pasa por tres estadios culturales en permanente tensión dialéctica: 1) un primer momento denominado por él Afroditismo, caracterizado por una promiscuidad natural y por el heterismo, durante el cual la madre aparece como el único principio cierto de generación. Se venera a las diosas de la tierra, pues la visión de mundo está fundada en la tierra y en su fuerza natural engendradora de toda vida. El matrimonio aún no existe, ya que es considerado como infracción de un precepto religioso (se considera cualquier exclusivismo como ofensa a la divinidad). 2) Sobre el Afroditismo se eleva el estadio Demétrico, en el que se desarrolla la ginecocracia, que aún venera a las diosas de la tierra pero en el que ya se ha llevado a cabo el paso a la agricultura y al matrimonio. 3) Finalmente, surge el estadio Uránico (patriarcalismo occidental) en el que la madre pasa de ser el principio de procreación a convertirse meramente en nodriza del germen paterno. 


\subsection{La madre Tierra}

Frente al mundo creado por el mandato del dios judío, se pondera en Sofía de los presagios un mundo nacido de la tierra (Terra Mater), dando lugar con ello a la presencia de un elemento constitutivo fundamental de la estructura psicosocial ginecocrática que subyace en la fábula de la novela.

Una breve mirada a la prehistoria permite constatar la presencia de una Diosa Madre que representa la vida, la muerte y la regeneración, símbolos todos de una comunidad preocupada por los problemas de la vida y del ciclo de la muerte. Así, los poderes productivos de la tierra generaron en tiempos prehistóricos divinidades predominantemente femeninas y ligadas a la fertilidad: Gea, Rea, Hera, Demeter para los griegos; Isis entre los egipcios y en las religiones helenísticas; Ishtar entre los asiriobabilonios; Astarté para los fenicios y los iberos; y Kali entre los hindúes (Chevalier y Gheerbrand 1986: 674).

Con la introducción del cristianismo, la figura femenina ocupa un nuevo lugar en el universo de las ideas y de los hechos:

\footnotetext{
El Jehová varón es un patriarca hebreo inflexible que no nos permite abrigar la menor duda acerca de la posición de la mujer. Lejos de ser madre de todas las razas de hombres, el orden natural se ha trastocado y la mujer ha surgido del hombre, reducida a mera costilla masculina (Figes 1980: 42).
}

La mujer queda así excluida del protagonismo en la esfera religiosa. Ella pasa ahora a ser sierva (María por antonomasia), y, por ejemplo, los ritos religiosos, tanto el hebraico como el cristiano, eran y son oficiados exclusivamente por hombres. Irónicamente, luego de ser la mujer la Diosa Madre, el falocentrismo la llevará a ser la destructora de la humanidad. El tristemente célebre inquisidor Jacobo Sprenger dirá: "Si investigamos, encontraremos que casi todos los reinos del mundo han sido destruidos por mujeres" (Figes 1980:67) y no satisfecho con esta afirmación concluirá: "Cristo Redentor descendió del Cielo para salvar exclusivamente al sexo masculino" (Figes 1980: 68).

Asimismo, en lo que respecta a nuestro sustrato indígena, la tierra también representa la fecundidad y la regeneración. Para los aztecas, la diosa Tierra es a la vez madre nutricia, porque permite vivir de sus frutos, y destrucción, porque reclama a sus muertos de los cuales se alimenta. En el caso de los mayas, el glifo de la tierra es la diosa de la luna (Ixchel), reina de los ciclos de la fecundidad. Esta diosa luniterrena tiene además una función primordial: es la señora del número 1, aquella que preside el nacimiento u origen de todas las cosas; y entre los incas también se cuentan divinidades femeninas como la diosa luna, quien, entre otros atributos, cuenta con el de ser la protectora de los partos (Chevalier y Gheerbrant 1986: 660, 993).

Sin embargo, ¿cómo se presenta esta ponderación a la Madre Tierra y los demás elementos constitutivos del mundo ginecocrático en Sofía de los presagios?

El incipit de la novela, a manera de semillero textual, nos revela importantes datos:

\footnotetext{
Es de noche y el mundo está quieto. Hay que entrar de puntillas al Diriá, pueblo de brujos, pueblo que crece sobre el cerro que en lo alto se quiebra y baja hacia la inmensa laguna de Apoyo. (...) Las puertas están cerradas y en el parque acampan los gitanos que vienen de la América del Sur, que vinieron antes de Europa, de Egipto y de la India y mucho antes del paraíso terrenal donde una gitana anterior a Eva encantó a Adán y parió una raza de hombres sin pecado original (Belli 1990: 11).
}

En primer lugar, tenemos el primado de la noche sobre el día. La antigüedad privilegiaba la noche para la lucha, la deliberación, la administración de justicia y la celebración de 
los cultos. Es durante la noche que los vericuetos del amor harán que los padres de Sofía la abandonen involuntariamente y la niña entre en un proceso doloroso de búsqueda de su centro. El devenir de los hechos nos mostrará a una Sofía estrechamente vinculada con la naturaleza, dada su relación con los brujos que la iniciarán en los ritos mágicos de la vida y de la muerte, y su vivencia de la maternidad en la procreación de su hija Flavia (posesión física-carnal a semejanza de la Madre Naturaleza con sus criaturas), en la cual se sucederá y vivirá la angustia de su pérdida.

Tanto el hecho de que Sofía tenga a su hija sin haber un matrimonio de por medio como el de que el padre desconozca el fruto de la unión sexual son datos que nos sitúan en un punto de tensión entre el mundo matriarcal —en donde el nacimiento es una verdad natural— y el patriarcal —en tanto la paternidad se convierte en este en una creación "espiritual"—. Para Bachofen, el derecho natural materno precede, de acuerdo con las leyes de la naturaleza, al derecho civil paterno; mientras que la madre es un hecho físico y semper certa, el padre es siempre una ficción jurídica e incertus (Bachofen 1988: 258).

Al finalizar el primer capítulo de la novela, sabemos de la existencia de Xintal, la bruja que habita el Mombacho, para quien la tierra es la mayor de las divinidades, la madre de todos los frutos y de toda la vida. Xintal declara: "Sólo la oscuridad de las almas extrañadas de la naturaleza, ha podido inventar un dios macho con una madre virgen, para quien el placer que produce la vida, es pecado" (Belli 1990: 147). Esta manifestación de Xintal advierte una confrontación de las dos estructuras psicosociales presentes en la novela: la matriarcal y la patriarcal.

La invocación de la Madre Antigua con el objeto de darle identidad a Sofía es, en la novela, la máxima expresión de esta historia milenaria en la que la tierra simboliza la función maternal: ella da y toma la vida:

\footnotetext{
Con el lodo negro de San Juan de Oriente y la vara, Samuel traza un círculo negro que abarca la casi totalidad del claro; Doña Carmen va regando sal sobre el círculo, al tiempo que Xintal lo riega de aguardiente de caña de azúcar. Una vez hecho esto, los tres se pintan las caras con el lodo negro, se pintan las cejas, los párpados y todo el rostro para que la luz no los deslumbre y los espíritus curiosos no les adivinen la identidad y lleguen después a invocarles favores. Una vez pintados, se toman de las manos y penetran al círculo negro y en el centro hacen otro círculo con las candelas de sebo serenado. Luego se sientan en el espacio detrás de las candelas y Samuel saca la vasija con el té de floripón y los tres van tomando grandes tragos hasta vaciarla y siguen sentados con las piernas cruzadas mientras sienten que el cuerpo se les va relajando, cierran los ojos y se ponen en contacto con la fuerza interior que les empieza a danzar en el vientre, en el estómago, en los pulmones con la euforia de verse liberada y suelta para bailar. Se ponen de pie y comienzan a dar pasos suavecitos, pasos de danzas remotas y con los ojos abiertos pueden ver los ojos de los árboles que son muchos y verde profundo y los saludan y les cantan. Bailan cada vez más rápido y la danza despierta a los pájaros azules que se enfilan y vuelan en círculo sobre el redondel que trazara Samuel con su vara y pronto hay una algarabía de insectos y mariposas nocturnas, pocoyas y lechuzas sobre la luz de las candelas. La luna se ha colocado ya en el cielo sobre el círculo de velas, Xintal da el último paso de baile, se detienen y ella entona el canto de llamada a la Madre Antigua (Belli 1990: 282-3).
}

Samuel traza un círculo negro sobre el cual derrama sal. El círculo es un símbolo universal de lo celestial, un arquetipo de totalidad, es signo de protección. El color negro nos remite a las diosas madres que a menudo se representan con este color en virtud de su carácter ctónico. Por su parte, la sal, tanto para los griegos como para los árabes y los hebreos (fuentes todos de nuestra cultura), es un símbolo de amistad y de hospitalidad porque es compartida (Chevalier y Gheerbrant 1986: 908).

Se hace inevitable en este punto recordar que para Robert Graves los mitos son recuerdos serios de costumbres y acontecimientos religiosos antiguos y tan dignos de confianza 
como la historia; asimismo, para Bachofen, el comienzo de toda evolución está en el mito. Sofía de los presagios ¿acaso nos advierte sobre algo?

\subsection{Entre círculos y espirales}

Frente a la concepción cristiana del tiempo como lineal e irreversible, aparece en Sofía de los presagios una repetición cíclica renovadora de signo pagano, propia del mundo arcaico, en la que las acciones humanas se consideran reproducción de un acto que ha sido planteado y vivido anteriormente por otro. La vida es, entonces, la repetición ininterrumpida de gestos inaugurados por otros.

Tu tiempo es un círculo. Lo que se vivió antes de vos, lo volverás a vivir y eso es peligroso (...) Ojalá rompás el tuyo. Tenés que buscar los símbolos, Sofía; encontrando tu pasado, encontrarás tu futuro... (Belli 1990: 102).

Esta visión del tiempo circular también es propia de la cosmovisión aborigen mesoamericana: tanto los mayas como los aztecas creían que la historia se repetiría siempre que los influjos divinos volvieran a estar en el mismo equilibrio: "Si la conjunción adecuada se produce, Sofía podrá romper el círculo y no repetir mitos prefabricados" (Belli 1990: 234). Asimismo, para los náhuatl el mundo había existido no una sino varias veces consecutivas, pero en esas sucesiones ocurría cierta evolución en espiral en la que seres humanos, plantas y elementos se perfeccionaban (León-Portilla 1974). Esto es fundamental para entender la ruptura del tiempo circular de Sofía: es a través de la espiral que ella logrará alcanzar su libertad y, de igual manera, su hija: "Flavia, que el destino no se tuerza y seas capaz de romper los círculos del tiempo y los abandonos que persiguen a tu madre" (Belli 1990: 342).

Mircea Eliade expone en su libro El mito del eterno retorno que, para las culturas arcaicas, el mundo que nos rodea tiene un arquetipo extraterrestre, celestial, y que las regiones desiertas habitadas por monstruos, mares desconocidos, etcétera corresponden a un modelo mítico asimilado al caos, al tiempo anterior a la creación. Por esta razón, cuando se desea habitar estos territorios, se efectúan ritos que repiten simbólicamente el acto de la creación. Es así como los brujos del Diriá, a manera de dioses que organizan y dan forma y normas al caos, deciden someter a Sofía a un ritual que le permite librarse de las contradicciones que la embargan a causa del abandono de sus padres:

Ellos tienen que convocar la columna de luz para que Sofía pueda salir de los campos oscuros y ver su propia imagen; tienen que llamar a la Madre Antigua para que Sofía pueda saber dónde está enterrado su ombligo y no se quede flotando sin dirección en el vacío de su propio desconcierto (Belli 1990: 280).

Las huellas de estos ritos ancestrales se encuentran también en la práctica cristiana (ya no pagana), pues el padre Pío, en nombre de Dios, acude al rito del exorcismo para "tomar posesión" de Sofía y dar lugar a su nuevo nacimiento:

\footnotetext{
El padre Pío rebusca en la sacristía los santos óleos. No tiene otros que los que usa para dar la extremaunción, pero igual que a la muerte se podrá espantar al demonio; toma el aspersor de agua bendita, la estola y el misal donde está escrito el rito del exorcismo, se persigna rogándole a Dios que le ilumine para salvar el alma que la misericordia divina le ha traído al templo, y sale haciendo la genuflexión al pasar por el medio de la nave (Belli 1990: 267).
} 
En el mundo arcaico, las concepciones metafísicas se formulan mediante símbolos, mitos y ritos. En este mundo, los objetos y las acciones no tienen valor intrínseco autónomo, sino que lo adquieren, y de esta forma llegan a ser reales. En el caso de los objetos, estos aparecen como receptáculos de una fuerza mágica o religiosa que los diferencia de su medio y les confiere sentido y valor:

Llega el turno a Samuel, quien realiza la ceremonia del rutu-chicoy. Con el cuchillo afilado corta un poco del cabello de la niña y luego con las tijeras corta sus uñas, poniéndolas en un lienzo blanco donde atan también los instrumentos, para luego entregar todo a Sofía, quien deberá conservarlos como amuleto porque desde ese instante han adquirido poderes mágicos (Belli 1990: 343).

Asimismo, los sucesos no pertenecen al azar, sino a ciertas influencias divinas, mágicas o demoníacas, contra las cuales el-la bruja o el-la sacerdotisa disponen de armas:

\begin{abstract}
Te voy a dar un remedio - dice Xintal (a Sofía), luego de un rato largo en que las dos mujeres han guardado silencio- Vas a agarrar treintisiete rosas y las vas a deshojar; los pétalos los vas a poner en agua hirviendo para que suelten y luego te vas a bañar lunes, miércoles y viernes a las nueve de la noche con esa agua. Mientras te bañás — y esto es lo más importante — vas a recordar algo agradable de tu vida; te vas a ver a vos misma feliz, riendo y hermosa y te vas a aferrar a esa imagen todo el tiempo que dure el baño (Belli 1990: 2712).
\end{abstract}

Si estas intervenciones no resultan, se ruega al ser supremo celestial. Así, los brujos del Mombacho, luego de analizar la situación de Sofía, acudir al agua de la poza de las adivinaciones y leer el Tarot, deciden invocar a la Madre Antigua:

Ellos tienen que convocar la columna de luz para que Sofía pueda salir de los campos oscuros y ver su pro-
pia imagen; tienen que llamar a la Madre Antigua para que Sofía pueda saber dónde está enterrado su om-
bligo y no se quede flotando sin dirección en el vacío de su propio desconcierto (Belli 1990: 280).

Conviene detenerse con mayor detalle en tres símbolos de este mundo antiguo cuya presencia en la novela son de gran peso; a saber: el centro, el círculo y la espiral. Con respecto al centro, Mircea Eliade nos habla de lo que él denomina el "simbolismo del centro": la Montaña Sagrada donde confluyen el cielo y la tierra, y todo templo, que también es una "montaña sagrada", se halla en el centro del mundo. En el caso de Sofía de los presagios, este está representado por el Mombacho (toponimia náhuatl: cerro inclinado) y por la ermita ubicada en lo alto del mirador de Catarina, desde donde baja Sofía al pueblo del Diriá a la mañana siguiente de ser abandonada por sus padres.

En la cosmogonía arcaica, se considera que el infierno, el centro de la tierra y la puerta al cielo se hallan sobre el mismo eje, pasando así de una región cósmica a otra. De manera que no es fortuito que Sofía tenga que bajar al Diriá (infierno) y afrontar el dolor, para luego subir al Mombacho (cielo) y encontrar su "centro", es decir, su yo, su origen (imagen). La tríada Catarina-Diriá-Mombacho sintetiza en la novela el punto de encuentro de las tres regiones cósmicas: el cielo, la tierra y el infierno. Estos lugares constituyen el escenario en donde se pasará de lo profano a lo sagrado, de la dependencia a la autonomía, de la oscuridad a la claridad:

Su cuerpo se volverá capullo y cuando el jaguar, la serpiente y el pájaro alcancen su madurez, podrá renacer y encontrar su centro (Belli 1990: 286).

Mircea Eliade apunta que "la consagración del "centro" se hace en un espacio cualitativamente distinto del espacio profano (...) así como el tiempo de un ritual cualquiera 
coincide con el tiempo mítico del "principio" " (Eliade 1985: 28); de ahí que, por ejemplo, las ceremonias del rocío y del rutu-chicoy (rituales de protección que se aplican a los niños a quienes es difícil predecir el futuro) tengan que realizarse en la montaña y "antes de que el sol emerja en el horizonte" (Belli 1990: 338).

Retomemos ahora la siguiente cita en la que Eulalia le habla a Sofía:

\begin{abstract}
Hay tiempos que suben en espiral, pero hay tiempos que giran en círculo. Eso pude ver en mi viaje hacia tu pasado. Tu tiempo es un círculo. Lo que se vivió antes de vos, lo volverás a vivir y eso es peligroso. Temele al amor y a sus arranques, temele a tus manos. Yo no sé cómo se rompen los círculos del tiempo. Soy muy vieja y los muertos ya nada podemos aprender, pero sé que hay círculos que se rompen. Los he visto desde las esquinas de la espiral donde muero, hay círculos que los vivos logran romper. Ojalá rompás el tuyo. Tenés que buscar los símbolos, Sofía; encontrando tu pasado, encontrarás tu futuro... (Belli 1990: 102).
\end{abstract}

En esta declaración de Eulalia, se encuentran reunidos los tres símbolos: el centro, el círculo y la espiral: el centro, puesto de manifiesto en el mandato de encontrar el pasado y con él, el futuro; en otras palabras, hallar los orígenes. El círculo, en tanto simboliza el tiempo que le corresponde a la vida de Sofía, pero que a pesar de su simbolismo positivo (perfección, protección, soplo divino), para Sofía significa una catástrofe; por eso debe romperlo, convertirlo en espiral y encontrar su centro. Las esquinas en donde se encuentra Eulalia, como manifestación del cuadrado, simbolizan la detención (Eulalia está muerta). Y, finalmente, la espiral, en tanto esta "manifiesta la aparición del movimiento circular saliendo del punto original; (...) como emanación, extensión, desarrollo, continuidad cíclica pero en progreso, y rotación creacional" (Chevalier y Gheerbrant 1986: 479). Además, no debe perderse de vista que la espiral también es un símbolo de fecundidad, acuática y lunar, que, marcada sobre los ídolos femeninos paleolíticos, homologa todos los centros de vida y fertilidad.

Eulalia habla de que hay tiempos que suben en espiral y otros que giran en círculo; el tiempo de Sofía es un círculo. Xintal dice:

\footnotetext{
Los seres humanos a los que nunca les hierve la sangre son fáciles de predecir, la línea no tiene posibilidad de alterarse (recordemos que el círculo es un punto extendido, una línea); pero en el caso de Sofía, hasta la poza de aguas calientes muestra imágenes contradictorias. Un día la ve feliz, al día siguiente desgraciada. Hay dos destinos que se atraen y rechazan. Existe la gravedad de la espiral aparentemente inconmovible, la línea circular de la que hablara Eulalia, buscando repetir el ciclo, pero por algún temblor del tiempo (el círculo simboliza el tiempo) hay un trazo de vida inacabado, un hueco por el que Sofía podría escapar de la repetición innumerable. Por eso ella le insiste a Doña Carmen que no todo lo que sucederá a Sofía "está en su destino". Si la conjunción adecuada se produce, Sofía podrá romper el círculo y no repetir mitos prefabricados (cosmogonía ancestral) (Belli 1990: 233-234. Cursiva nuestra).
}

Los destinos que se atraen y rechazan y el círculo inconcluso (el trazo de vida inacabado) responden a una visión dialéctica. Esta es justamente la que le permite a Sofía acceder a una vida en espiral (Chevalier y Gheerbrant 1986: 480). El resultado de la ceremonia de invocación a la Madre Antigua sintetiza la dialéctica del encuentro de estos dos símbolos: el círculo y la espiral:

\footnotetext{
Xintal ve el corazón de Sofía convertirse en un pájaro de plumas multicolores y el cordón de luz volverse una serpiente que se enrolla (espiral) alrededor del jaguar que le sale del ombligo (círculo, centro) (Belli 1990: 285. Cursiva nuestra).
}

De esta forma, Sofía llega al final de su búsqueda, puede mirar su imagen en el espejo, reconciliarse con la oscuridad de su origen, romper las profecías y empezar a vivir su 
propia vida. Su hija Flavia fue el medio que le permitió encontrar el agujero abierto en la fatalidad y lograr que ambas se salvaran de la repetición de los mitos prefabricados (Belli 1990: 373-4).

\subsection{El rostro femenino de la luna}

Frente al astro sol (dominio masculino), aparece en Sofía de los presagios la luna (dominio femenino), en consonancia con la existencia de un mundo ginecocrático. La conexión entre la supremacía de uno u otro de los astros y la relación entre los sexos es característica en el desarrollo de la cultura; de ahí que Bachofen señale al sol como el astro que preside la evolución del principio paterno (victoria de la ideología patriarcal), mientras que al astro de la noche lo asocie con la mujer, pues simboliza la potencia fecundante de la vida (Bachofen 1988: 107).

Asimismo, la luna, al estar ligada a la noche, ocupa un lugar de mediación que la antigüedad consideraba la región fronteriza entre dos mundos: es el pasaje de la vida a la muerte y de la muerte a la vida; por eso, numerosas divinidades lunares son al mismo tiempo ctónicas y funerarias. Es por esta razón que los brujos del Diriá escogen la noche para convocar el espíritu de Eulalia con el propósito de destrabar el corazón de Sofía y lograr que esta encuentre su centro: "Faltan quince minutos para las doce — dice Samuel. Guardaremos silencio, pensaremos en Eulalia y a las doce empezaremos" (Belli 1990: 98).

Ahora bien, la luna también es luz en la inmensidad tenebrosa. Pero su luz no es propia sino reflejo de la del sol; por lo tanto, es símbolo del conocimiento por reflejo, no intuitivo sino conceptual. Por eso se relaciona con el simbolismo de la lechuza ligada a los adivinos y a su don de clarividencia mediante el cual interpretan signos (Chevalier y Gheerbrant 1986: 633).

\footnotetext{
Los tres tienen la visión de Eulalia saliendo a través del lugar donde el cono de luz se inserta en la tierra y llegando a la cama donde Sofía duerme embrocada sobre sí misma en posición fetal, con el sueño pesado que la columna de luz ha hecho posarse sobre los habitantes de la zona esa noche. Eulalia entra a la habitación y toma a Sofía en sus brazos como si no pesara y fuera una niña pequeña, luego la lleva a una mecedora y empieza a mecerse con ella en los brazos al tiempo que canta canciones de cuna. Eulalia aprieta a Sofía contra su pecho, le acaricia la cabeza, le soba el pecho hasta que una luz apenas perceptible comienza a brotar entre las costillas de la muchacha y se va concentrando para formar un cordón de luz que va de su corazón a su ombligo. Xintal ve el corazón de Sofía convertirse en un pájaro de plumas multicolores y el cordón de luz volverse una serpiente que se enrolla alrededor del jaguar que le sale del ombligo. Samuel, por ser hombre, sólo presiente las visiones de las dos mujeres y tiene una sensación confusa que le hace mover los labios como cuando era niño y lactaba (Belli 1990: 285).
}

La luna es un símbolo que concierne a la sacralidad religiosa de la mujer y a la potencia generadora de la vida encarnada en las distintas divinidades de la fecundidad que se funden en el culto de la Diosa Madre:

La luna se ha colocado ya en el cielo sobre el círculo de velas, Xintal da el último paso de baile, se detienen los tres y ella entona el canto de llamada a la Madre Antigua:

"Bendícenos madre porque somos tus criaturas.

Bendice nuestros ojos para que veamos la belleza invisible.

Bendícenos la nariz para oler tus perfumes.

Bendícenos la boca para que digamos las palabras mágicas.

Bendícenos el pecho para que lata nuestro corazón en armonía con las plantas.

Bendice nuestras piernas, bendice nuestros sexos creadores de la vida.

Bendice nuestros pies para que bailen la alegría de la cosquilla.

Bendice esta noche para que la luz venga hasta aquí y la que no tiene madre encuentre su ombligo" (283). 
Concluida la invocación a la Madre Antigua, sabemos que mujeres, hombres y animales entran en un sueño profundo; la naturaleza se viste de calma, parece que espera que ocurra algo:

\footnotetext{
Los hombres y mujeres insomnes de los pueblos vecinos sienten como los vence el sueño luego de tanto desearlo; se duermen profundamente (...) La laguna se queda quieta, se detiene el viento, y del centro del agua surge magnífica la columna de luz. Primero como si un faro hubiera encendido su ojo en la profundidad de la laguna lanzando un haz luminoso recto hacia el cielo, pero pronto las partículas de luz se mueven con fuerza centrífuga y forman un tornado luminoso que se levanta sobre el agua, sube al medio del cielo y empieza a moverse despacio, como si bailara, en dirección del Mombacho (284).
}

Surge entonces el simbolismo de la luna ligada al sueño y a lo inconsciente. Chevalier y Gheerbrant (1986: 662) señalan que "el complejo simbólico lunar e inconsciente asocia a la noche los elementos agua y tierra, con las cualidades de frío y de humedad, por contraposición al simbolismo solar y consciente, el cual asocia al día los elementos aire y fuego y las cualidades de calor y sequía". De manera que, en este contexto signado por elementos constitutivos del mundo ginecocrático, no es casual la presencia de la laguna (agua: fuente de vida, medio de purificación y centro de regeneración) en cuyo seno surge la luz (luna: principio femenino) como un símbolo de iluminación y claridad que al convertirse en un tornado (que se dirige hacia la montaña: centro) nos advierte sobre la evolución que tendrá lugar en la vida de Sofía, no controlada por ella sino por fuerzas superiores, en este caso la Madre Antigua, a la que se ha invocado para que Sofía nazca de nuevo y encuentre su centro:

\footnotetext{
Doña Carmen, Xintal y Samuel sienten que la mente se les abre y que cada uno puede sentir los pensamientos de los otros y hasta los pensamientos pequeños y claros de los pájaros y mariposas. Los tres tienen la visión de Eulalia saliendo a través del lugar donde el cono de luz se inserta en la tierra y llegando a la cama donde Sofía duerme embrocada sobre sí misma en posición fetal, con el sueño pesado que la columna de luz ha hecho posarse sobre los habitantes de la zona esa noche. (...) Eulalia mece y mece a Sofía y a su canto gutural se unen las voces de Doña Carmen y Xintal a quienes el vientre les empieza a doler con el recuerdo de los partos. Xintal sabe que la Madre Antigua las está preñando para que vuelvan a dar a luz a la Sofía y ésta pueda renacer con un nuevo corazón que sea la unión de serpiente, jaguar y pájaro (Belli 1990: 285-6).
}

De esta forma, la presencia de la luna nos sitúa ante un universo mental ginecocrático donde emergen el diálogo con la naturaleza, el primado de la noche sobre el día nacido de su regazo, la elección de la noche para los cultos, la preferencia por los muertos a quienes se invoca para resolver los sucesos, el ligamen con la madre (primigenia y terrenal, las sacerdotisas buscan una madre para Sofía) que se extiende a ámbitos mayores que convergen en la fraternidad universal. En resumen, "la luna aclara el camino, siempre peligroso, de la imaginación y la magia” (M.C. citado en Chevalier y Gheerbrant 1986: 663). ¿El poder mágico de las mujeres?

\section{Desarticulación del sistema patriarcal en Sofía de los presagios}

\subsection{El regreso de las brujas}

En una entrevista a Gioconda Belli efectuada por Ignacio González Janzen (1990), titulada "El arte de volar", a la pregunta "¿Y cómo encajan las escobas voladoras, los jinetes y las mujeres barbudas en tu militancia feminista?", la escritora respondió: 
No hay ninguna contradicción, sino todo lo contrario. Yo diría que la magia nos permite convertir la escoba, que es un símbolo de la opresión doméstica de la mujer, nada menos que en un objeto volador que nos permite elevarnos en libertad.

Sin embargo, la consecución de esta libertad le ha costado a la mujer siglos de variopinta represión y estigmatizaciones, entre ellas, la de bruja. Grande debe ser el temor de los varones al "aparente" poder mágico de las mujeres que, por ejemplo, G.R. Quaife en su libro Magia y Maleficio. Las brujas y el fanatismo religioso (1989) anota que "son alrededor de cuarenta las interpretaciones de la esencia o etiología de la bruja que merecen ser tenidas en cuenta (13)".

La novela Sofía de los presagios aparece justo una década antes de terminar el siglo $\mathrm{XX}$ y nos relata la historia de una bruja moderna. La figura de la bruja es recuperada y releída en un contexto que abre la discusión acerca de lo transgresor y amenazante que resulta el conocimiento de sí mismo y de los secretos de la naturaleza en una sociedad marcada por la razón patriarcal.

No obstante, ¿qué se entiende por bruja? Si nos ceñimos a su etimología, en español, de acuerdo con el diccionario de la Real Academia de la Lengua, bruja significa: lechuza, ave nocturna. Bruja también es el nombre dado en Murcia a la más sutil y menuda arena que se saca de las acequias cuando se limpian; en consecuencia, nos remite a lo escatológico. Y por último, bruja es la mujer que, según la opinión vulgar, tiene pacto con el diablo y, por su intermedio, hace cosas extraordinarias.

La psicóloga y feminista española Victoria Sau (1981: 45) agrega a estas definiciones sobre la figura de la bruja lo siguiente:

\footnotetext{
En su calidad de unidad simbólica dentro de un sistema de representaciones, la bruja es el reverso del ha$\mathrm{da}$, generalmente joven y hermosa. Usa esta última sus poderes mágicos para conceder dones que en el fondo son cualidades que el sistema exige en los individuos (véase cómo es dotada por ejemplo, la Bella Durmiente del Bosque) o bien que premia estas cualidades con bienes extraordinarios. El hada suele aparecer como muy femenina, como imagen o modelo de lo que se entiende por la buena madre. La bruja en cambio, es percibida como poco femenina porque se aparta del modelo de mujer creado por el patriarcado. Desobedece al sistema puesto que se atreve a tener poder (mágico) y esta desobediencia la afea a los ojos de quienes son desobedecidos; este poder la convierte asimismo en la antítesis de la mujer-hija propia del incesto padre-hija patriarcal, y esto hace que sea percibida también, como vieja.
}

Estas apreciaciones contrastan con quienes se han tachado de brujas en todas las culturas y en todos los tiempos: mujeres vinculadas estrechamente a los poderes telúricos, conocedoras profundas de los ritmos de la vida, de la sexualidad, de la fecundidad; mujeres como las comadronas, las herbolarias, las curanderas. Pero el conocimiento que poseen estas mujeres les confiere poder; por lo tanto, resultan amenazantes para el orden y el poder establecido, el cual se encuentra en manos de los varones. Las mujeres se convierten entonces en brujas, en seres diabólicos que deben ser confinados del ámbito público.

Eva Fidges señala que los mitos de la creación anteriores al Génesis otorgaban a la mujer una importancia que luego la mitología hebraica trasladaría al hombre y nos remite al Antiguo Testamento en el que, según dice, se evidencian vestigios de un matriarcado anterior (Figes 1980: 35).

Probablemente, para muchos de los que se han formado en la tradición religiosa cristiana, el nombre de Lilith resulte desconocido, y más aún, si se asocia a Adán como su primera compañera. La única mujer que la historia ha legitimado junto a Adán es Eva; sin embargo, 
los textos apócrifos cuentan que Jehová realizó dos tentativas frustradas antes de crear a la Eva definitiva, pues ninguna de las anteriores fue del gusto de Adán y la primera, Lilith, resultó demasiado rebelde. La tradición cuenta que Lilith fue creada de la tierra conjuntamente con Adán, a quien abandonó poco tiempo después porque quería completa igualdad con su marido y no tener hijos. Esto le valió a Lilith quedar viviendo como un demonio que odiaba a los recién nacidos y les hacía daño. Su nombre significa "monstruo de la noche" y su origen se remonta al demonio asirio-babilónico Lilit o Lilú (Sau 1981: 144).

Esta primera mujer, y a la vez la primera mujer-demonio (monstruo), aparece en el incipit (semillero de la construcción textual) de Sofía de los presagios. Allí se declara que "una gitana anterior a Eva encantó a Adán y parió una raza de hombres sin pecado original” (Belli 1990: 11). Este dato es muy importante para la historia que se narra en esta novela por las siguientes razones: 1) el admitir la existencia de una mujer primigenia distinta de Eva nos sitúa frente a un texto subversivo, pues cuenta una historia diferente de la oficial; 2) Sofía, la protagonista, desciende de los gitanos; por lo tanto, es portadora de los secretos y poderes de un pueblo estrechamente ligado a la magia y al espíritu de la naturaleza; y 3) el hecho de que no existiera "pecado original" en la procreación de esta raza advierte una relación distinta con la sexualidad, la cual aún no se ha convertido en algo diabólico ni sucio y mucho menos ligado a la mujer de forma negativa.

Sin embargo, los temores patriarcales se organizan de manera que lo anterior tenga una lectura distinta; por eso Patrocinio (del latín patrocinium: defensa, en este caso del orden establecido) se apura a advertirnos que tanto esta primera mujer como sus descendientes los gitanos (Sofía en este caso) no son de fiar: "Son como el judío errante", dice Patrocinio y se persigna; "pongámosle candelas a la virgen", dice, "vamos a la iglesia". Y salen las mujeres del pueblo a rezar en el sereno de la mañana" (Belli 1990: 13).

Estamos entonces frente a una escisión: dos tipos distintos de mujer, dos maneras distintas de relación con la naturaleza, dos formas diferentes de ver la sexualidad. El patriarcado ha escindido en dos la imagen de la mujer y al hacerlo también fractura su relación con la naturaleza y con la sexualidad; de esta manera, frente a la mujer angélica, virtuosa, cuya única relación con la sexualidad y la naturaleza es la de ser madre, aparece la mujer demoníaca, la bruja fabricante de historias que traspasa el reducto de lo doméstico para convertirse en una mujer poseedora de la palabra y de los secretos de la vida y la reproducción. Se instaura así la dicotomía mujer natural-erótica/mujer bíblico-cristiana virtuosa.

El microcosmos del pueblo de superchería hipócrita del Diriá sintetiza los conflictos que se derivan de esta escisión en las figuras de Sofía y Gertrudis (ver pág. 16 de la novela). Sofía se nos presenta como una mujer que lucha por definirse a sí misma y no a partir o en función de los otros, opuesta a "fingir ser una apacible mujer casada" (Belli 1990: 63) y, por el contrario, dispuesta a decidir sobre su cuerpo y su maternidad, por lo que para los habitantes del Diriá y para René, su marido, será una mujer diabólica (Lilith), "machorra":

Fácil le había salido al diablo meterles una hija de las tinieblas en el pueblo con aquel cuento de que los gitanos la habían dejado botada. ¡Y el pobre René haberse casado con ella! Patrocinio recordaba muy bien las historias del día de la boda. A Crescencio y a ella no los habían invitado gracias a Dios, pero toda la gente había compadecido al pobre René teniéndose que casar con aquella mujer sucia. A quién se le iba a pasar desapercibido el designio satánico de que no se casara de blanco, sino llena de tierra, con polvo hasta en las pestañas. Y no es que René fuera la gran maravilla, pero era un buen muchacho, ni peor ni mejor que todos los demás. Y ¡claro que no le iba a tener un hijo a él esa mujer! Seguro que el diablo subiría cualquier noche a preñarla. No debían ser casualidades todas las desgracias que habían pasado en el país durante tantos años y, para colmo, aquella cosa arisca de la tierra que le agarraba por estar temblando o dejándose arrasar por huracanes (70. Subrayado nuestro). 
Gertrudis, por su parte, lucha por cumplir su papel de mujer virtuosa (virtud viene de "vir" (varón)):

\footnotetext{
Desde que Doña Carmen le propusiera darle algo para conseguir lo que quiere, (Gertrudis) se ha pasado debatiendo entre golpes y contragolpes de su conciencia entrenada para no desviarse jamás del camino de la virtud (129).
}

Sin embargo, toda mujer angélica lleva un monstruo adentro y a la inversa; por eso, Gertrudis, quien ciertamente en el Diriá no sería vista como bruja, sí se tornará en algún momento en hechicera, es decir, en una joven con el atractivo sexual y la belleza oportunas para que el varón (René) esté dispuesto a someterse a sus hechizos como a una prueba ritual de confirmación de su virilidad. La sexualidad que despierta la hechicera no es amenazante para el varón, no socaba su poder, sino que es placentera y gozable (48):

\footnotetext{
De cuando en cuando (René) dirige su mirada hacia Gertrudis y sonríe complacido, pensando cómo no se habría fijado en ella antes, esa mujercita sí tenía madera de esposa, de hembra paridora y buena mamá, no como la Sofía que ni siquiera tenía la decencia de aparecerse y saludar a la gente que venía a darle el pésame por la muerte del papá (120).
}

Con la llegada del cristianismo y sus distintos estadios de desarrollo, concretamente los siglos XIV y XV con la Inquisición, las brujas pasan a ser herejes. En 1484, el Papa Inocencio VIII promulgó su célebre bula Summis desiderantes, y desató así la guerra de la Iglesia católica contra la antigua religión. Cinco años después, con la publicación del Malleus Maleficarum (El martillo de las brujas) se sientan las bases y los procedimientos para perseguir, enjuiciar y quemar personas sospechosas, especialmente a las mujeres y sus hijos, pues se creía que estos heredaban el "mal" de sus madres. La hechicería campesina de encantamientos y sortilegios se vinculó entonces a una conspiración diabólica que pretendía derrocar la cristiandad (Quaife 1989: 32-3).

Los inquisidores alemanes Jacob Sprenger y Heinrich Kramer, que redactaron el $M a$ lleus Malleficarum, recurrieron a la etimología de la palabra "fémina" para demostrar que la mujer era un instrumento del demonio para la perdición de los hombres. Su argumento fue: "fémina" viene de fe-minus, o sea, la que tiene menos fe. Esta clara manipulación de las palabras no hace sino ejemplificar lo que Rosemary Radford Ruether (citada por Yadira Calvo en A la mujer por la palabra) entiende por lenguaje y la influencia de este en la perpetuación del patriarcado: "la reflexión fundamental del poder del grupo dominante para definir la realidad en sus propios términos y reducir a los grupos oprimidos a la invisibilidad" (Radford Ruether en Calvo 1990: 16).

En América, como en Europa, el "oficio" de bruja ha pasado a ser una práctica subterránea; consecuentemente, se han perdido algunas de las tradiciones y olvidado otras. Sin embargo, una nueva generación de mujeres y hombres ha iniciado un proceso de recuperación de las "magas" mediante la celebración de la vida, de los ciclos naturales, los cambios de estación. Se ha vuelto a cantar a la Diosa Madre, a la Terra Mater.

Sofía de los presagios es un buen ejemplo de este retorno. Sofía, la protagonista de la novela, es una bruja del siglo XX, heredera del poder gitano (Viejo Mundo) y del hechizo tropical de América (Nuevo Mundo). El viaje por los senderos de esta confluencia de mundos mágicos, Sofía lo hará de la mano de tres brujos del Diriá: doña Carmen, la adivina y curandera del pueblo; Samuel, "maestro de hechicerías, el brujo más famoso del Diriá” (Belli 1990: 
85); y Xintal, "una vieja también de leyenda que solo de vez en cuando bajaba al pueblo y a quien todos recordaban haber conocido desde lejanas infancias, sin que el tiempo pareciera hacer mella sobre sus facciones arrugadísimas de siempre" (141).

Doña Carmen es la encargada de leer a Sofía las cartas que predicen su futuro y ensenarle los secretos del Tarot, un juego de cartas antiquísimo lleno de símbolos medievales y cristianos:

Te salen la muerte y la torre — dice doña Carmen—. Alguien tendrá que morir y muchas cosas serán destruidas. Es la purificación a través del fuego...Vas a sufrir mucho. Está en tu destino. Pero vas a conocer el amor" (53).

Samuel, por su parte, es el iniciador de Sofía en los secretos de la magia de la carne. Al amparo de "un guayacán cuya copa baja forma una especie de pequeño refugio" (174) (simbolismo sexual del árbol), Samuel construye una fogata (el fuego como elemento purificador propio de los ritos iniciáticos de muerte y renacimiento) y luego echa en esta las flores de amapolas salvajes (símbolo de la fecundidad) que ha cortado en el camino:

Sofía se acerca. Entre los dos se han establecido corrientes cómplices y subterráneas avivadas por la noche, la luna y el fuego (174).

Finalmente, Xintal prepara a Sofía para la vida a través del conocimiento de los secretos de la tierra, de la lectura de los signos que aparecen en las pozas azules que hay en el Mombacho y del amor a la Madre Antigua:

La Diosa anida en el vientre de las mujeres y en el falo de los hombres, porque allí es donde comienza la vida desde donde todo lo demás se genera (...) Ella ha sido bruja por generaciones, le dice. Las brujas están encargadas de conservar la sabiduría ancestral de las mujeres, que desde tiempos remotos, antes de que se las persiguiera y se las obligara a la docilidad, veneraban la tierra y conocían el secreto de las buenas cosechas, los poderes mágicos de las plantas y las entrañas de ciertos animales (147).

Sofía ahora es portadora de nuevos conocimientos; pero, entre estos, el entendimiento de los secretos de la magia de la carne es el que la torna más peligrosa ante los ojos del pueblo. La sexualidad a lo largo de la historia de la humanidad se ha convertido en un punto neurálgico de ataque a la mujer; esta se vincula a una sexualidad incontrolada vista como lo más odiado y temido. El inquisidor Sprenger señalaba que la maldad natural de la mujer radica en su lujuria insaciable (Figes 1980: 66):

\footnotetext{
-La muy desvergonzada- dice Patrocinio, dando a conocer la noticia a todo el que se acerca a la cantinahaciendo sus cochinadas en el mirador, a la vista y paciencia de todo el mundo. Una puta es lo que es esa bruja" (Belli 1990: 223. Subrayado nuestro). "Pobre mujer! Hay gente en el pueblo que no vacilaría en volver al tiempo de las hogueras y el potro de los españoles. La quemarían sin remordimiento, persignándose y entonándole cantos a la Virgen -rezonga Samuel-. Ya hasta me han venido a pedir que la enferme para que el diablo se la lleve de una vez (86).
}

La asociación de la mujer con la sexualidad que no busca solo la procreación sino también el placer provoca la aparición de una mujer mala, una bruja. El contacto sexual con brujas tiene repercusiones terribles para el hombre. Con ella se asociaban la aparición de enfermedades venéreas, esterilidad, impotencia y hasta castraciones fantasmales. No es gratuito entonces que René no pudiera "alumbrarle las entrañas" a Sofía, y tampoco es fortuito que su 
matrimonio fracasara. La iglesia, que santifica el matrimonio con miras a la procreación, tiene ante sus ojos la presencia del demonio.

Cuando Sofía, imbuida en su pena de amor por Jerónimo acude a la iglesia como dice ella a "arreglar sus negocios con Dios", el Padre Pío no encuentra más camino que el de practicarle un exorcismo. Pero para Patrocinio, la dueña de la cantina a donde llegan según Engracia los hombres a emborracharse para luego ir a sus casas a "malmatar a las pobres mujeres", Sofía sigue siendo una bruja:

\footnotetext{
-A mí que ni se me acerque- dice Patrocinio-. Yo le pongo candelas a la Virgen diario para rogarle que se la lleve de aquí...Para colmo dicen que anda penando un mal de amor! Seguro que quiere dar a creer que fue un hombre el que la panzoneó y no el mismo diablo! (269).
}

Pero la maternidad de Sofía también será estigmatizada, pues su origen es impropio: el hijo no es de René, su legítimo aunque no amado marido, sino producto de su "lujuria" (sexo como algo sucio y diabólico). De manera que no se trata solo de que la mujer cumpla con su "función" de reproductora, sino también de que cumpla con una preceptiva generada al respecto.

Lilith se negó a hacer el amor en la postura del misionero y se convirtió en el primer ejemplo de mujer "emancipada"; Pandora dio al mundo las calamidades; Eva fue responsabilizada de la mortalidad del hombre y de la pérdida de su estado de gracia, y María, por su lado, fue condenada a ser virgen. Pero Sofía presagia tiempos nuevos para la mujer, tiempos en que pueda "mirar su imagen en el espejo, reconciliarse con la oscuridad de su origen, romper las profecías y empezar a vivir su propia vida” (Belli 1990: 374-5).

A las puertas del siglo XXI, Gionconda Belli escribe:

En verdad en verdad les digo:

No hay nada más poderoso en el mundo

Que una mujer.

Por eso nos persiguen.

“Máxima”, poema perteneciente al libro Apogeo.

\subsection{El gran teatro de los roles}

Frente a los estereotipos construidos por la cultura patriarcal y falocéntrica occidental (dios, hombre), emerge en Sofía de los presagios una figura que sintetiza la apropiación por el principio masculino del principio femenino (principio dialéctico de la unión de los contrarios): Fausto. Su presencia pone de manifiesto que el establecimiento de roles e intereses diferentes en razón del sexo obedece a un artificio cultural que limita las posibilidades humanas.

La construcción de la sexualidad está marcada por un sistema de poder y de lucha que hace que las "culturas construyan categorías, esquemas y nombres diferentes para encuadrar las experiencias sexuales y afectivas" (Schifter y Madrigal 1996: 34), y aquellos hombres y mujeres que no se atengan a estas pueden exponerse a situaciones amenazantes. Tal es el caso de Fausto, quien carga con el estigma del "sexo equivocado" (Belli 1990: 34) en un pueblo en el que hombres como René luchan por afirmar su virilidad.

Fausto, al no asimilar los discursos sexuales establecidos, es decir, al no traducirlos en acciones "propias" del macho como la presencia en la cantina, en la pandilla o en los 
prostíbulos, se expone a las fobias de un pueblo chico y "creyencero" como el Diriá. Pero en la misma medida, René, al pretender afirmarse como semental y no lograrlo dada la negativa de Sofía al embarazo, se expone al vituperio y, peor aún, a la lástima:

\section{él solo pensaba en que la gente iba a creer que para nada ocupaba su virilidad, aquel miembro grandote que se le repintaba en los pantalones y que lo había hecho famoso en la escuela donde le apodaban "el tor- cudo"... (70).}

En este sentido, Jacobo Schifter (1994: 18) señala en su artículo "La máscara de la masculinidad" que el enorme temor que sienten los varones a la idea de que su "masculinidad" no sea lo suficientemente fuerte (y anota que en realidad nadie sabe cuál es el modo real de la masculinidad) es lo que los hace llevar una máscara puesta, y agrega: "Mientras la llevemos, perdemos la oportunidad de ser humanos". La vida se convierte así en un gran teatro en donde se aprende a "ser varón o a ser mujer".

En el mismo tenor, Mario Mieli (1979:39) señala que en la cultura falocéntrica rige una norma monosexual marcadamente heterosexual, la que es transmitida de generación en generación a lo largo del proceso de socialización, que él denomina "educastración". La mutilación del Eros y la condena de la homosexualidad son sus soportes. En este sentido, el siguiente pasaje de la novela se torna muy elocuente:

\footnotetext{
-Tu ex anda buscando novio -dice Patrocinio a René, el viernes que él llega a la cantina-. Vieras como anda, toda pintada, con ropa nueva, sandalias de tacón, bailando las nalgas para marear a todos los estúpidos que parecen jugados de cegua cuando la ven" (...) "la Sofía se gastó un dineral en Managua comprando ropa y el maricón de Fausto, al no poder vestirse él de mujer, se ha dedicado a asesorarla. Hasta dicen que él mismo la viste con sus propias manos, y la pinta (Belli 1990: 194-5).
}

La sexualidad de la mujer se convierte entonces en lo más odiado y temido; de ahí que rameras y diablesas sean la misma cosa y que, a su vez, los homosexuales sufrieran implacables persecuciones que fueron de la hoguera a la horca. Un texto bíblico nos advierte sobre este punto de encuentro creado por el falocentrismo para juntar homosexuales y mujeres en un mismo sitio:

\footnotetext{
Por esto Dios los entregó a pasiones vergonzozas; pues aun sus mujeres cambiaron el uso natural por el que es contra naturaleza, y de igual modo también los hombres, dejando el uso natural de la mujer, se encendieron en su lascivia unos con otros, cometiendo hechos vergonzozos, hombres con hombres, y recibiendo en sí mismos la retribución debida a su extravío (Epístola del Apóstol San Pablo a los Romanos, Cap. I, vers. 26-7).
}

La condena de la homosexualidad parece que se origina en el mundo hebraico y ha llegado a nosotros a través del cristianismo. Recordemos el pasaje de Sodoma y Gomorra que, nota aparte, no solo pone en evidencia el antihomosexualismo sino también el desprecio por la mujer, pues el "buen" Lot prefiere canjear a sus hijas (cosificación de la mujer) a cambio de la salvación de los ángeles (masculinos). Agreguemos, además, que luego las hijas son expuestas al incesto, lo que nos sitúa ante la práctica de una doble moral: el homosexualismo no, el incesto sí.

La homosexualidad fue una práctica frecuente e incluso sagrada en la antigüedad, pero, en el devenir histórico, ha sufrido la misma suerte que la imagen de la mujer. Por ejemplo, en el plano religioso, así como hubo homosexualidad sagrada también hubo divinidades 
femeninas que luego el mundo falocéntrico convirtió en deidades masculinas aparecidas primero como hijos y más tarde como imagen paterna. Durante siglos, el suplicio de la hoguera, en memoria del incendio de Sodoma, fue la pena señalada por las legislaciones y los códigos para castigar a los homosexuales; pero la mujer no solo se ha visto lanzada a la hoguera sino que, además, ha cargado con la responsabilidad de haber convertido al hombre en mortal y conducirlo a la pérdida de su estado de gracia; por esto deberá parir con dolor, su deseo será el de su marido y él reinará sobre ella (Mieli 1979).

En la Edad Media, tanto homosexuales como mujeres fueron tachados de diabólicos; su presencia era sinónimo de vicio, perversión y deshonra. Eran herejes, personas a las que se les acusaba de vicios contra natura. Varios siglos después, en un país que vive los estragos de una revolución, lastimosamente nos encontramos con un Fausto abatido porque: "Ser homosexual en Nicaragua es ser un íncubo, hijo del diablo, hombre de tres patas, payaso, encarnación de la anti-naturaleza" (Belli 1990: 66).

Los calificativos negativos van cercando el mundo de la homosexualidad y arrinconándolo hacia el de la prostitución, pues, para muchos de los "normales", la heterosexualidad es a la procreación como la homosexualidad al vicio y a la prostitución; de hecho, la mala mujer es la puta o la lesbiana: "Bruja, cochina", "Puerca", "Muera la puta y su chivo". "Mueran los cochones" son las palabras que a grandes letras ensucian la cal blanca del muro de la hacienda" (241).

Fausto, Sofía y René nos ayudan a entender cómo "la cultura construye sexualidades que reflejan su estructura de pensamiento y los pensamientos reflejan la cultura en que se construyen" (Schifter y Madrigal 1996: 51). La novela se desarrolla en una Nicaragua sumida en un proceso revolucionario que abre las puertas a otros tipos de discursos sobre la sexualidad; la evidencia es que en el mundo falocéntrico de los finqueros experimentados y soberbios del Diriá, un homosexual y una mujer les han demostrado, entre otras cosas, que pueden manejar una finca y obtener tan buenas o mejores cosechas que las de ellos y que los estigmas son un artificio para mantener un estado de cosas deseado por la cultura patriarcal.

\section{Sofía: una señal de cambio}

Sofía de los presagios es una mujer muy distinta de la Sofía rousseniana. El hecho mismo de que su nombre, sinónimo de sabiduría, se encuentre acompañado de un epíteto que indica, previene y anuncia cambios, advierte que nos encontramos frente a una figura y a un texto que nos revelan algo.

A través de la experiencia femenina de Sofía en el mundo mágico y recóndito del Diriá, se evidenciarán distintas relaciones de poder (sea este político, entre sexos o entre distintas cosmovisiones) en un contexto marcado por una revisión profunda de las estructuras que conforman la sociedad; tal es el caso de la Nicaragua que sirve de telón de fondo para la narración de esta historia y que parece vibrar, al igual que Sofía, en dos planos espacio-temporales: el actual y global del proceso de la revolución sandinista y el atemporal y local de la magia del Diriá.

La carga de significación de Sofía de los presagios trasciende el mero placer poético y nos sitúa ante una curiosa simbiosis entre literatura y política en Nicaragua. Once años después del triunfo de la revolución sandinista, aparece en 1990 en librerías esta segunda novela 
de Gioconda Belli, en la que ya no se plantea el debate de la conciencia (Itzá-Lavinia en La mujer habitada) por sobreponerse a sí misma para incorporarse a un proyecto personal (exploración de lo femenino) y político (el proceso insurreccional), sino la visión de una Nicaragua cuya revolución no ha podido penetrar en algunos sectores de profundas raíces mágicas como es el caso del Diriá y su protagonista Sofía. Una Sofía diferente dentro de la diferencia, cuya presencia provoca en el pueblo la aparición de tres bandos: "el que acepta su infortunio, el que sigue augurando desgracias para cuando ella crezca y las que acostumbradas a la magia deciden tomarla bajo su protección" (Belli 1990: 22), es una metáfora de la Nicaragua fracturada que busca su centro y desea empezar su propia vida.

Al igual que en el resto de Centroamérica, tanto la contrucción social de lo femenino como el modelo de familia están permeados por el sincretismo de los valores indígenas y de los patriarcales. En el espacio de las relaciones humanas, marcadas por el sexismo y el machismo, esto se traduce en un alto porcentaje de madres jefas de hogar, pues, en una gran cantidad de casos, los varones están ausentes tanto económica como afectivamente, situación que se torna alarmante en el medio rural, donde el ciclo embarazo-parto-lactancia casi no tiene tregua y se agudiza con el estado de subalimentación de las mujeres (Murguialday 1990: 10).

Sin embargo, la actitud beligerante de las mujeres ha sido también una constante en la historia de Nicaragua. Por ejemplo, para el triunfo de la Revolución Sandinista (1979), las mujeres representaban el $51 \%$ de la población de Nicaragua, y a la vez, a los sectores más empobrecidos y analfabetas. El triunfo del Frente Sandinista creó múltiples expectativas y se consolidó en logros importantes, algunos de los cuales detallaremos a continuación, mediante la homologación de la realidad histórica con la novela en estudio, sin perder de vista las distintas reacciones que todo este proceso generó.

La consecución de los objetivos prioritarios de reconstrucción y reactivación económica del país perseguidos por el FSLN incluyeron, entre otras acciones, la promulgación de la ley de Cooperativas y la de Reforma Agraria (1981). La primera establecía explícitamente que las mujeres podían asociarse en igualdad de condiciones que los hombres y participar sin restricciones. La segunda fue la primera ley de este tipo en América Latina que reconocía a las mujeres como sujetos y beneficiarias directas de las políticas agrarias, sin exigirles que fueran jefas de hogar o que tuvieran hijos varones adultos para participar de sus beneficios, lo cual se ve reflejado en la novela en estudio (Murguialday 1990: 78): "Desde la mentada revolución todas las mujeres se creían moneditas de oro, independientes. ¡La putería era lo que se había fomentado con esas leyes!"' (Belli 1990: 152).

Asimismo, en el año 1979, se promulga el Estatuto de Derechos y Garantías cuyo artículo 3 establecía el marco jurídico necesario para hacer efectiva la igualdad salarial entre los sexos:

\footnotetext{
Las mujeres de los mozos, retrecheras al principio hasta de acercarse a la casona, ahora friegan pisos y descuelgan telarañas porque ella (Sofía) les ha prometido pagarles y antes sólo a sus maridos les pagaban (160).
}

También en 1979, se crea en el Ministerio de Trabajo el Departamento de Salud Ocupacional de la Mujer, entre cuyos logros puede citarse la aplicación por primera vez de los subsidios por maternidad, cuatro semanas antes y ocho después del parto. Pero al acabar la guerra, la maternidad vuelve a ocupar su lugar en la vida de las mujeres nicaragüenses; por eso, 
la política sanitaria puesta en marcha con la creación del Sistema Nacional Único de Salud (SNUS) fue prioritaria para ampliar la cobertura de los servicios médicos gratuitos, tratar la problemática del aborto clandestino y la planificación familiar (Murguialday 1990: 84,87). En este sentido, véase la siguiente cita de la novela: "Si es más afortunada, logrará que Gertrudis le traiga de Masaya las famosas píldoras donadas por las Naciones Unidas y que, según el periódico, están de venta en todas las farmacias" (Belli 1990: 43).

Las mujeres nicaragüenses se beneficiaron también con la revisión de instrumentos legales de gran importancia pero obsoletos para la época, como el Código Civil de Nicaragua (1881), que en relación con el matrimonio estipulaba relaciones y responsabilidades asimétricas para los sexos, traducidas en la práctica cotidiana en una historia de madres y abuelas condenadas a la pobreza y al trabajo agotador, como producto de la irresponsabilidad paterna que tiene fundamentos económicos e ideológicos (Murguialday 1990: 25; Dore 1997):

\begin{abstract}
René la observa y piensa que es orgullosa la mujercita, pero que el orgullo se le vencerá con el tiempo y con los hijos que tendrán que llegar porque él cumple religiosamente con su parte de hombre preñador, copulando con ella todas las noches aunque esté cansada, aunque ella no haga ningún ruido y sólo se quede inmóvil debajo de él con los ojos abiertos viendo para el techo como una estatua fría y be1la (Belli 1990: 47).
\end{abstract}

Otro cambio significativo fue la aprobación del divorcio por mutuo consentimiento o a petición de una de las partes (1987), pues, según el procedimiento vigente, el hombre, con solo acusar a su mujer de adulterio, conseguía el divorcio, mientras que la mujer debía demostrar que este tenía una amante que vivía en su propia casa (Murguialday 1990: 26):

\footnotetext{
¡Desvergonzada hija de mala madre que se atrevía a exhibirlo como imbécil delante de toda Nicaragua, en aquella edición que circulaba a lo largo y ancho del territorio nacional! Él hasta había estado dispuesto a perdonarle la escapada e instalarla bien cuando la encontrara, darle una casa, si ella quería separarse, porque ahora con lo de la Gertrudis, hasta bien le salía lo de la separación: ella podía quedarse sola, si esa era su voluntad, y él irse a vivir con la Gertrudis a otra parte, sin causar tanto escándalo. Pero eso del divorcio era distinto. La Sofía era su mujer para siempre y aunque no viviera con ella y él viviera con otra, sus derechos nadie podía quitárselos. Seguro la rufiana tendría algún querido. ¿Para qué se iba a querer divorciar una mujer decente? (Belli 1990: 151. Subrayado nuestro).
}

Otra lacra del sistema patriarcal que fue abolida es el artículo 263 del Código Civil nicaragüense, el cual, en caso de separación o divorcio, otorgaba al varón y no a la madre la patria potestad, con sólo probar que él había reconocido y criado a los hijos (Murguialday 1990: 32).

\footnotetext{
-Es que yo no quiero andar dejando hijos regados, Doña Patrocinio, no quiero -y golpea un puño sobre la mesa-. No quiero, ipero por Dios que no me va a quedar de otra!".

-Una cosa es tenerlos y otra dejarlos regados -dice Doña Patrocinio-. Vos los podés tener y no desconocerlos; les das tu nombre, los criás...y además, la Sofía, ¿qué te va a poder decir? Vos estás en tu derecho. No es culpa tuya que ella sea machorra (Belli 1990: 71- 2. Subrayado nuestro).
}

Estrechamente ligada a la vida de pareja, o dicho en forma más amplia, a la esfera de los afectos con el otro sexo, y por encima de lo vivido en Nicaragua en sus distintos procesos revolucionarios, este país comparte con otros de Latinoamérica una sobrevaloración de la maternidad y la censura a las mujeres que no la consideran dentro de sus aspiraciones. Es claro que este hecho tiene sus raíces en la religión y en las necesidades del mundo rural, donde los hijos representan fuerza de trabajo: 


\begin{abstract}
-Mi mujer es machorra, doña Patrocinio -le dice-, arrastrando la voz que parece quedársele atascada entre los dientes.

-Y qué, pues, ¡qué perdés vos que sea machorra! Vos no sos el culpable. Si tanto querés tener un hijo, tenélo con otra mujer. ¡Sobra quien quiera tener hijos en este país!

Ya él lo ha pensado. Tiene incluso vistas varias perspectivas, pero en el fondo, teme comprobar la acusación de Sofía de que es él y no ella la razón de que no lleguen los hijos (Belli 1990: 72. Subrayado nuestro).
\end{abstract}

Sofía ha decidido no tenerle hijos a René, a pesar de que él "todas las noches, con callada determinación, se da vuelta hacia ella y copula como si se tratase de una parte impostergable del contrato matrimonial" (Belli 1990: 43), pues ella intuye que si esa violación da lugar a un hijo, quedará atada psicológica y materialmente a ese hombre, y que esa maternidad será el sello de su "encarcelamiento". René la ha "encarcelado" en la casa, ha basado su poder en la fuerza y demanda de Sofía su obediencia, convirtiéndola en una suerte de esclava: "Me hacés el favor de no salir. De esta casa no volvés a salir si no es conmigo" (Belli 1990: 40).

Sin embargo, Sofía ha sabido construir "su habitación propia", tanto en el orden práctico como simbólico:

Con la ayuda de Petrona, la doméstica, Sofía se pasa el resto de la tarde jalando mesitas y mecedoras de los otros cuartos y se hace un lugar para ella sola. Le dirá a René que es su cuarto de costura, piensa, y lo arreglará con plantas y con sus cosas para tener al menos una parte de la casa donde se sienta ella misma; un lugar para esconderse de la infelicidad y de René (Belli 1990: 41).

Y en la aparente tranquilidad del cuarto de costura empieza a tejer la telaraña de su independencia al amarrar distintos puntos que se relacionan con su entorno mágico: el conocimiento de las hierbas, la lectura de las cartas del Tarot y la sabiduría ancestral de las mujeres vertida en los secretos de la cocina; puntos todos alejados y enlazados a la vez a un centro que, en una hermosa metáfora, simbolizan su propio centro.

La contraportada de la edición de Sofía de los presagios que utilizamos para este estudio dice: "El sino marca la vida de esta mujer que sufre muchos sinsabores para romper, ella misma, con el sortilegio". Ciertamente esta apreciación puede aplicarse también a la historia de Nicaragua; pero, en ambos casos, la ruptura es con algo mucho más fuerte que la metáfora del sortilegio. Se trata de todo un sistema de imposiciones que provienen de una esfera externa que dicta lo que se debe ser y lo que debe hacerse. Nicaragua luchó por definirse a sí misma y Sofía hizo su parte al demostrar que su lugar en la sociedad era el de un sujeto activo, con palabra y decisiones propias, cuya aparente incompleción no radica en su naturaleza femenina sino en la falta de centro, en el conocimiento de sí misma y en la capacidad de establecer una relación intergenérica equitativa y armónica, tal como lo propone la misma Gioconda Belli en su "Invitación feminista":

\footnotetext{
Ninguna sombra entre nosotros medie.

Ven.

Alzate conmigo hasta el cenit.

Mírame desde la misma altura.

Juntos apaciguaremos la muerte.

Juntos enterneceremos las piedras.

Juntos abriremos el mar.

Nos tomaremos la Tierra Prometida.

Incendiaremos el rostro de los siglos.
} 


\section{Bibliografía}

Ávila Romero, Mauricio. 1993. "Sofía de los presagios: la Nicaragua profunda". El día latinoamericano, México, Año 3, núm. 100 (11 de enero): p. 19.

Bachofen, Johann Jacob. 1988. Mitología arcaica y derecho materno. España: Editorial Anthropos.

Belli, Gioconda. 1990. Sofía de los presagios. Nicaragua: Editorial Vanguardia.

1991. El ojo de la mujer. Nicaragua: Editorial Vanguardia.

1997. Apogeo. Managua: Anamá Ediciones Centroamericanas.

Calvo, Yadira. 1990. A la mujer por la palabra. Costa Rica: Editorial de la Universidad Nacional (EUNA).

Chevalier, Jean y Alain Gheerbrant. 1986. Diccionario de los símbolos. Barcelona: Editorial Herder, S.A.

Dore, Elizabeth. 1997. "Unidades familiares, propiedad y política en la Nicaragua rural: Diriomo (1840-1880)". En: Entre silencios y voces. Género e historia en América Central (1750-1990). San José: Centro Nacional para el Desarrollo de la Mujer y la Familia: pp. 21-40.

Eliade, Mircea. 1985. El mito del eterno retorno. Arquetipos y repetición. Traducción de Ricardo Anaya. Madrid: Alianza Editorial, S.A.

Figes, Eva. 1980. Actitudes patriarcales: Las mujeres en la sociedad. Madrid: Alianza Editorial, S.A.

Gimbutas, Marija. Diosas y dioses de la vieja Europa 7000-3500 a.C. Mitos, leyendas e imaginería. Ediciones Istmo: 99-271.

González Janzen, Ignacio. 1990. “Gioconda Belli: El arte de volar”. En Diario Barricada, Suplemento Gente, Managua, núm. 10 (8 de febrero): p. 3.

González, Victoria. 1997. "Mujeres somocistas: "La pechuga” y el corazón de la dictadura nicaragüense (1936-1979)". En: Entre silencios y voces. Género e historia en América Central (1750-1990). San José: Centro Nacional para el Desarrollo de la Mujer y la Familia: pp. 197-216.

Gutiérrez Rojas, Marisol. 1999. La obra narrativa de Gioconda Belli o el poder mágico de las mujeres. Tesis de Maestría: Universidad de Costa Rica. 
James, E. O. 1972. Historia de las religiones. Madrid: Ediciones Guadarrama, S. L.

La Santa Biblia. 1977. C.I. Scofield (ed.). Georgia: Editorial Publicaciones Españolas.

León-Portilla, Miguel. 1974. La filosofía náhuatl. México: Universidad Nacional Autónoma de México.

1975. "Religión de los nicaraos". El pez y la serpiente. Revista de Cultura. Núm. 15: pp.7-52.

Mieli, Mario. 1979. Elementos de crítica homosexual. Barcelona: Editorial Anagrama.

Monte Ávila Editores Latinoamericana (ed.). 1993. Diosas, musas y mujeres. Caracas: Monte Ávila Editores Latinoamericana.

Murguialday, Clara. 1990. Nicaragua, revolución y feminismo (1977-89). Madrid: Editorial Revolución.

Quaife, G.R. 1989. Magia y maleficio. Las brujas y el fanatismo religioso. Barcelona: Editorial Crítica, S.A.

Real Academia Española. 1984. Diccionario de la lengua española. Madrid.

Russotto, Márgara. 1990. Tópicos de retórica femenina. Caracas: Monte Ávila Editores y Centro de Estudios Latinoamericanos Rómulo Gallegos (CELARG).

Sau, Victoria. 1981. Un diccionario ideológico feminista. Barcelona: ICARIA Editorial, S.A.

Schifter, Jacobo. 1994. "La máscara de la masculinidad". Mujer/Fempress, Latinoamérica. 153 (julio): p. 18.

Schifter, Jacobo y Johnny Madrigal. 1996. Las gavetas sexuales del costarricense y el riesgo de infección con el VIH. San José: IMEDIEX.

\section{Otras fuentes}

Entrevista personal a Gioconda Belli. Managua, Nicaragua, 19 de julio de 1995.

National Film Board of Canada. The burning times. Witches. Donna Read (productora). 1990. (documental) 